\title{
The Development of Treatment for Parkinson's Disease
}

\author{
Harishankar Prasad Yadav', Yun Li ${ }^{2 *}$ \\ ${ }^{1}$ Department of Clinical Medical College, Dali University, Dali, China \\ ${ }^{2}$ Department of Neurology, The Affiliated Hospital, Dali University, Dali, China \\ Email: drharishankaryadav@gmail.com,
}

Received 17 June 2015; accepted 4 August 2015; published 7 August 2015

Copyright (C) 2015 by authors and Scientific Research Publishing Inc.

This work is licensed under the Creative Commons Attribution International License (CC BY).

http://creativecommons.org/licenses/by/4.0/

\section{(c) (i) Open Access}

\begin{abstract}
Parkinson's disease (PD) is a slowly progressive, age-related, second most common neurodegenerative disorder after Alzheimer's disease of unknown etiology. Dopamine replacement therapies were introduced five decades ago and still remain the mainstay of treatment for Parkinson's disease. However, with long-term treatment with L-dopa, more than $50 \%$ of patients were found to develop motor response complications approximately after 4 - 5 years of initiation of continuous treatment, in $80 \%$ of patients treated for 10 years, and in nearly $100 \%$ patients with young-onset disease. The complications of long-term treatment with levodopa include-motor fluctuations, dyskinesias, and nonmotor fluctuations are such as mood disturbance, cognitive dysfunction, dysautonomia and pain. Till date, there are various therapeutic approaches having been developed for the treatment of advanced PD comprising Pharmacotherapy, neurotrophic factors, surgical procedures such as DBS, cell-based therapies and gene therapies. The pharmacological and surgical therapies are only aiming to improve the symptoms of PD, but none are proven to have a significant effect on the underlying disease process with respect to either slowing disease progression or restoring the affected dopaminergic neurons. Although there is no cure for PD, Gene based therapy has significant prospective advantages over the conventional treatment modalities for PD, as it could theoretically be used to preserve or restore dopaminergic neurons affected by PD through the action of neurotrophic factors or alternatively increase the availability of enzymes required for dopamine synthesis. All commonly employed PD therapies focus on the amelioration of symptoms and do not cure disease. In this review only we summarize the newer therapeutic strategies for the treatment of PD such as anti-inflammatories, neurotrophic factors, neurosurgical procedures (DBS), cell based therapies and gene therapies.
\end{abstract}

\section{Keywords}

Parkinson's Disease, Neurotrophic Factors, DBS, Stem Cell Therapy, Gene Therapy

\footnotetext{
${ }^{*}$ Corresponding author.
} 


\section{Introduction}

Parkinson's disease (PD) is a slowly progressive, age-related, second most common neurodegenerative disorder worldwide, after Alzheimer's disease (AD) of unknown etiology [1]-[4]. PD was first described by James Parkinson in 1817 in his "An essay on the Shaking Palsy" and it was reported in 1893 that the symptoms of PD were attributable to severe degeneration of dopaminergic neurons in the substantia nigra pars compacta. [5]. PD affects approximately 1.5 million people in the United States, 1.7 million people in China and 4 million people worldwide with approximately $1 \%$ to $2 \%$ of the global population over 60 years of age and $4 \%$ of those older than 80 years with an annual incidence of 16 - 19 cases per 100,000 [6]-[9].

The etiology of PD still remains unclear, but it is thought that it may be caused by a combination of genetic and environmental factors. Genetic factors-genetic mutations, including alpha-synuclein (SNCA), Parkin (PARK2), PINK1(PARK7), DJ-1(PARK6), Leucine-rich repeat kinase 2 (LRRK2), ATP13A2 (PARK9), UCHL1, VPS35, GBA (glucocerebrosidase), DNAJC6, SYNJ1, ATXN2, ATXN3, MAPT, GCH1, DCTN1etc. and environmental factors, including age, sex, blood urate levels, NSAID use, head trauma, anxiety disorders, exposure to lead, manganese, iron, copper, solvents and pesticides (e.g. rotenone, paraquat, maneb, dieldrin, pyrethroids, organophosphates and Combined ambient exposure to ziram and paraquat) may be an important risk factor for PD which induce oxidative stress, mitochondrial dysfunction, $\alpha$-synuclein fibrillization and neuronal cell loss [10][14].

Parkinson disease is a multisystem disorder, clinically characterized by motor and non-motor (NM) symptoms. The motor symptoms of PD include four cardinal features: bradykinesia, rest tremor, rigidity, postural instability and gait impairment.

1. Bradykinesia: refers to slowness of movements with a progressive loss of amplitude or speed during attempted rapid alternating movements of body segments.

2. Rest tremor (sometimes also called Parkinsonian tremor) is a rhythmic oscillatory involuntary movement that comes about when the affected body part is relaxed and supported by a surface, thus removing the action of gravitational forces.

3. Rigidity: refers to an increased muscle tone felt during examination by passive movement of the affected segment (limbs or neck), involving both flexor and extensor muscle groups.

4. Postural and gait impairment: Parkinsonian patients tend to adopt a stooped posture owing to the loss of postural reflexes, a major contributor to falls [15] [16].

Non-motor (NM) symptoms, including autonomic disturbances (gastrointestinal, urogenital, cardiac, respiratory), sensory, skin, sleep, visual, neuropsychiatric dysfunctions (dementia, anxiety symptoms, depression, psychosis, impulse control disorders (ICDs), disorders of sleep wakefulness, apathy), olfactory dysfunction, and REM sleep behavior disorder (RBD), etc. [17]-[19].

The pathological hallmark of PD is the presence of intraneuronal proteinaceous inclusions called Lewy bodies (LBs) or Lewy neurites (LNs) in the substantia nigra and in several central nervous systems [20]. The main protein component of LBs is $\alpha$-synuclein, a synaptic protein with the propensity to misfold and aggregate. $\alpha$-Synuclein a small protein (140 amino acids) encoded by the SNCA gene which is the best known isoform of the synuclein protein family is a typical intrinsically disordered protein, but can adopt a number of different conformational states depending on conditions and cofactors. These include the helical membrane-bound form, a partially-folded state that is a key intermediate in aggregation and fibrillation, various oligomeric species, and amorphous aggregates. The misfolded protein behaves like a template inducing conformational change in the wild type proteins causing a cross-reaction and leading to neurodegeneration. Histologically, there is neuronal loss in the substantia nigra pars compacta along with compensatory astrocytic and microglial proliferation and biochemically there is loss of dopaminergic termini in the striatum [21]-[23].

Parkinson's disease imposes significant demands not only for patients but also for those people living and caring for them, who often have a reduction in their quality of life, where their social activities and work schedules reduce to be more involved in caring [24]. Depression is the most common psychiatric disorder associated with PD but is often under diagnosed and under treated leading to worsening of symptoms and deterioration of the quality-of-life of the people suffering from this disease [25]. Impulse control disorders (ICDs) and apathy are recognized as two important neuropsychiatric syndromes associated with PD may have a significant effect on patients with PD and their carers and are associated with significant psychiatric morbidity. The contribution of these behavior disorders to carer burden is less understood [26] [27].

Dopamine replacement therapies were introduced five decades ago and still remain the mainstay of treatment for Parkinson's disease [28]. Most therapies are oriented towards symptomatic relief aiming to slow or even 
terminate neurodegeneration and therefore cause slow progression of disease and do not cure disease. However, with long-term treatment with L-dopa, more than 50\% of patients were found to develop motor response complications approximately after 4 - 5 years of initiation of continuous treatment, in $80 \%$ of patients treated for 10 years, and in nearly $100 \%$ patients with young-onset disease [29]. The complications of long-term treatment with levodopa include-motor fluctuations, dyskinesias, and nonmotor complications such as mood disturbance, cognitive dysfunction, dysautonomia, and pain [30] [31]. The severity of motor complications has become promisingly more challengeable for the neurologists and many researchers are involved in the development of newer and more effective therapeutic strategy to minimize the complications related to levodopa treatment. Till date, various therapeutic strategies have been developed for the treatment of advanced PD, including Pharmacotherapy, neurotrophic factors, surgical procedures such as DBS, Cell-based therapies and gene therapies. The goal of this review is to emphasize the development of various therapeutic approaches and will focus only on newer treatment strategies for PD. This review mainly highlights the newer therapeutic methods for the treatment of PD such as anti-inflammatories, neurotrophic factors, surgical procedures (DBS), stem cell therapies and gene therapies.

\section{Literature Review}

\subsection{Anti-Inflammatories}

Neuro-inflammation and oxidative stress play a key role in the pathophysiology of PD and are characterized by activated microglia and infiltrating $\mathrm{T}$ cells at the site of neuronal injury, which is a prominent contributor to the pathogenesis of progressive PD. Microglia play a critical role in forming a self-propelling cycle leading to sustained chronic neuroinflammation and driving the progressive neurodegeneration in PD [32]. In Parkinson's disease pathophysiology, activated glia affects neuronal injury and death through the production of neurotoxic factors like glutamate, S100B, tumor necrosis factor alpha (TNF- $\alpha$ ), prostaglandins, reactive oxygen nitrogen species. As the disease progresses, inflammatory secretions recruit neighboring cells, including astrocytes and endothelial cells, resulting in a vicious cycle of autocrine and paracrine amplification of inflammation leading to neurodegeneration. The exact mechanism of these inflammatory mediators in the disease progression is still incompletely understood [33]. There are various anti-inflammatory agents have been developed for the treatment of Parkinson's disease which is described below:

\subsection{Statins}

Statins are cholesterol-lowering agents, but play a potential role in neuroprotection, immunomodulation, and anti-inflammation. Studies have demonstrated that Neuro-inflammation and associated infiltration of inflammatory cells into the central nervous system are inhibited by 3-hydroxy-3-methyl glutaryl co-enzyme A (HMG-CoA) reductase inhibitors. For the study, 6-Hydroxydopamine (6-OHDA)-treated pheochromocytoma-12 (PC12) cells were used to investigate the neuroprotective nature of simvastatin and lovastatin. These studies have identified that they significantly decreased both the mRNA and the protein levels of NMDAR1, TNF- $\alpha$, IL- $1 \beta$, IL-6 mRNA, COX-2 and protein expression levels in 6-OHDA-stimulated PC12 cells. Thus, these data have provided that simvastatin or atorvastatin may be of therapeutic benefit for the treatment of Parkinson's disease [34]-[36].

\subsection{Silymarin}

Silymarin is a complex of flavonolignans derived from the seeds of the plant Silybum marianum and has mainly antioxidant, anti-inflammatory, cytoprotective and neuroprotective effects. Silymarin treatment showed a non-monotonic dose-response curve and only 50 and 100 mg/kg doses preserved dopamine levels (62\% and 69\%, respectively) after MPTP intoxication. Silibinin, a major active constituent of silymarin, which decrease striatal caspase-3 and NFkB expression indicating potential anti-apoptotic and anti-inflammatory effects respectively. Additionally, Silibinin (100 and $200 \mathrm{mg} / \mathrm{kg}$ ) reduces MPP (+)-induced motor deficits such as fine motor movements and gait. It significantly diminishes the number of apoptotic cells and preserves dopaminergic neurons in the substantia nigra of MPTP-intoxicated mice. Thus, the authors suggested that silibinin play a pivotal role in the neuroprotective effect in the MPP (+) induced striatal toxicity augmenting dopamine and may be effective in the treatment of PD [37] [38].

\subsection{Berberine}

Berberine is an isoquinoline alkaloid isolated from Berberis vulgaris L., is known to act as an anxiolytic, anal- 
gesic, anti-inflammatory, antipsychotic, antidepressant and anti-amnesic effects. The study has demonstrated that treatment with berberine at maximal $50 \mathrm{mg} / \mathrm{kg}$ improved short-term memory by inhibiting apoptosis in the hippocampus and may serve as a potential therapeutic strategy for the alleviation of memory impairment and motor dysfunction in patients with PD [39].

\subsection{Mucuna Pruriens (MP)}

Mucuna pruriens is a leguminous plant is used as an anti-inflammatory drug. The study evaluated to see the neuroprotective effect of an ethanolic extract of MP seed in the 1-methyl-4-phenyl-1,2,3,6-tetrahydropyridine (MPTP) model of PD. MP treatment recovered the number of TH-positive cells in both the SN region and the striatum while reducing the expression of iNOS and GFAP in the SN. Treatment with MP significantly increased the levels of dopamine, DOPAC and homovanillic acid compared to MPTP intoxicated mice. MP down regulates NO production, neuroinflammation and microglial activation and all of these actions contribute to the MP's neuroprotective activity. Thus, the study has suggested that MP can be an effective treatment for neurodegenerative diseases, especially PD by decreasing oxidative stress and possibly by implementing neuronal and glial cell interference [40].

\subsection{Acetylcorynoline}

Acetylcorynoline is the major alkaloid component derived from Corydalis bungeana, a traditional Chinese medical herb. It has been shown to have anti-inflammatory properties, but no studies have yet described the effects of acetylcorynoline on PD. Experimental data showed that treatment with up to $10 \mathrm{mM}$ acetylcorynoline does not cause toxicity in animals. Studies have demonstrated that acetylcorynoline significantly decreases the dopaminergic neuron degeneration induced by 6-hydroxydopamine in BZ555 strain; prevents $\alpha$-synuclein aggregation; recovers lipid content in OW13 strain; restores food-sensing behavior, dopamine levels; and prolongs lifespan in 6-hydroxydopamine-treated N2 strain, thus showing its potential as a possible antiparkinsonian drug [41].

\subsection{Luteolin}

Luteolin 3', 4', 5, 7-tetrahydroxyflavone, is a common flavonoid that exists in many types of plants including fruits, vegetables, and medicinal herbs. The food-derived compounds luteolin has multi-target actions, including antioxidant, anti-inflammatory and neurotrophic activities. The study showed that when PC12 cells were pretreated with luteolin $(20 \mu \mathrm{M}) 30$ min prior to 6-OHDA (100 $\mu \mathrm{M})$ exposure, 6-OHDA-induced ROS overproduction, cytotoxicity, caspase-3 activation, mRNA expression of BIM, TRB3 and GADD34 were significantly attenuated leading to decreases in phospho-eIF2 $\alpha$, ATF4, GRP78 and CHOP and these results have suggested that diminishing intracellular ROS formation and down-regulation of p53, UPR and Nrf2-ARE pathways and it may be involved in the neuroprotective effect of luteolin [42].

\subsection{N-Butylidenephthalide}

N-Butylidenephthalide is the naturally-occurring component derived from the chloroform extract of Angelica sinensis. It has been shown to have anti-tumor and anti-inflammatory properties, but no reports have yet described the effects of n-butylidenephthalide on PD. The Study was demonstrated in PD animal models and found that n-butylidenephthalide significantly attenuates dopaminergic neuron degeneration induced by 6-hydroxydopamine; reduces $\alpha$-synuclein accumulation; recovers lipid content, food-sensing behavior, dopamine levels; and prolongs lifespan of 6-hydroxydopamine treatment, thus revealing its potential as a possible antiparkinsonian drug blocking egl-1 expression to inhibit apoptosis pathways and by raising rpn-6 expression to enhance the activity of proteasomes. Thus, the authors suggested that n-Butylidenephthalide may be one of the effective neuroprotective agents for the treatment of Parkinson disease [43].

\subsection{Curcumin Derivative}

CNB-001, a novel pyrazole derivative of curcumin, has recently been reported to possess various neuroprotective properties. The study was designed to investigate the neuroprotective mechanism of CNB-001 in a subacute 1-methyl-4-phenyl-1,2,3,6-tetrahydropyridine (MPTP) rodent model of PD. Administration of MPTP (30 mg/kg for four consecutive days) exacerbated oxidative stress, motor impairment and reduced tyrosine hydroxylase (TH), dopamine transporter, and vesicular monoamine transporter 2 (VMAT2) expressions. Pretreatment with CNB-001 
(24 mg/kg) not only ameliorated behavioral anomalies, but also synergistically enhanced monoamine transporter expressions and cosseted mitochondria by virtue of its antioxidant action. Thus, the authors suggested that the neuroprotective property of CNB-001 may have strong therapeutic potential for the treatment of PD [44].

\subsection{Lenalidomide}

Lenalidomide has shown protective effects in an animal model of amyotrophic lateral sclerosis, and its mechanism of action involves modulation of cytokine production and inhibition of NF-kB signaling. In order to assess the effect of lenalidomide in an animal model of PD, mThy1- $\alpha$-syn transgenic mice were treated with lenalidomide or the parent molecule thalidomide at $100 \mathrm{mg} / \mathrm{kg}$ for 4 weeks. This protective action was accompanied by a reduction in microgliosis both in the striatum and hippocampus. A central expression of pro-inflammatory cytokines were diminished in lenalidomide-treated transgenic animals, together with reduction in NF- $\kappa \mathrm{B}$ activation. Thus, the authors suggested that lenalidomide might have a therapeutic potential for reducing maladaptive neuroinflammation in PD and related neuropathologies [45].

\section{3. $\alpha$-Lipoic Acid (LA)}

$\alpha$-lipoic acid (LA) is a pleiotropic compound with potential pharmacotherapeutic value against a range of pathophysiological insults. Its protective actions against oxidative damage by scavenging ROS and reducing production of free radicals have been reported in various in vitro and in vivo systems. The study showed that the ability of LA to protect PC12 neuronal cells from toxicity of 1-methyl-4-phenylpyridinium (MPP+), the neurotoxic metabolite of 1-methyl-4-phenyl-1,2,3,6-tetrahydropyridine (MPTP) and inhibits intercellular ROS levels and the mitochondrial transmembrane permeability (Table 1). Thus, the authors suggested that LA play an

Table 1. Summary of anti-inflammatory agents with their mechanisms of actions for the treatment of PD.

\begin{tabular}{|c|c|}
\hline Agents & Mechanisms of Action \\
\hline $\begin{array}{l}\text { Statins } \\
\text { (Atorvastatin or Simvastatin) }\end{array}$ & $\begin{array}{l}\text { Decrease both the mRNA and the protein levels of NMDAR1, TNF- } \alpha \text {, IL-1 } \beta \text {, IL-6 mRNA, } \\
\text { COX-2 and protein expression levels in 6-OHDA-stimulated PC12 cells. }\end{array}$ \\
\hline \multirow{2}{*}{ Silymarin } & $\begin{array}{l}\text { Decreases striatal caspase- } 3 \text { and NFKB expression indicating potential anti-apoptotic } \\
\text { and anti-inflammatory effects respectively. }\end{array}$ \\
\hline & Additionally, it reduces MPP (+)-induced motor deficits such as fine motor movements and gait. \\
\hline Berberine & $\begin{array}{l}\text { It is known to act as an anxiolytic, analgesic, anti-inflammatory, antipsychotic, } \\
\text { antidepressant and anti-amnesic effects. }\end{array}$ \\
\hline \multirow{3}{*}{ Mucuna pruriens (MP) } & Reduces the expression of iNOS and GFAP in the SN. \\
\hline & $\begin{array}{l}\text { MP down regulates NO production, neuroinflammation and microglial activation. It also increases } \\
\text { the levels of dopamine, DOPAC and homovanillic acid compared to MPTP intoxicated mice. }\end{array}$ \\
\hline & $\begin{array}{l}\text { It has been shown to have anti-inflammatory properties, but no studies have } \\
\text { yet described the effects of acetylcorynoline on PD. }\end{array}$ \\
\hline Acetylcorynoline & $\begin{array}{l}\text { significantly decreases the dopaminergic neuron degeneration induced by 6-hydroxydopamine in BZ555 } \\
\text { strain; prevents } \alpha \text {-synuclein aggregation; recovers lipid content in OW13 strain; restores food-sensing } \\
\text { behavior, dopamine levels; and prolongs lifespan in 6-hydroxydopamine-treated N2 strain. }\end{array}$ \\
\hline Luteolin & Diminishes intracellular ROS formation and down-regulation of p53, UPR and Nrf2-ARE pathways. \\
\hline N-Butylidenephthalide & $\begin{array}{l}\text { Attenuates dopaminergic neuron degeneration induced by 6-hydroxydopamine; } \\
\text { reduces } \alpha \text {-synuclein accumulation; recovers lipid content, food-sensing behavior, } \\
\text { and dopamine levels; and prolongs lifespan of 6-hydroxydopamine treatment. }\end{array}$ \\
\hline Curcumin derivative & $\begin{array}{l}\text { Reduces tyrosine hydroxylase (TH), dopamine transporter, and vesicular monoamine } \\
\text { transporter } 2 \text { (VMAT2) expressions by virtue of its antioxidant action. }\end{array}$ \\
\hline Lenalidomide & Modulates cytokine production and inhibit NF-кB signaling. \\
\hline$\alpha$-lipoic acid (LA) & $\begin{array}{l}\text { Inhibits intercellular ROS levels and the mitochondrial transmembrane permeability } \\
\text { and reduce the production of free radicals to protectfrom the oxidative damage. }\end{array}$ \\
\hline
\end{tabular}

The table shows the summary of various important anti inflammatory agents with their mechanisms of action for the treatment of PD. 
important role to protect dopaminergic neuronal cells against oxidative damage [46].

\section{Neurotrophic Factors}

Neurotrophic factors (NTFs) or neurotrophins are endogenous proteins which are a subset of growth factors that play a pivotal role in the development, survival, differentiation and maintenance of specific neuronal cells in the developing and adult nervous systems that have the potential ability to protect degenerating dopamine neurons as well as promote regeneration of the nigrostriatal dopaminergic systems [47] [48]. The family of neurotrophins consists of nerve growth factor (NGF), brain-derived neurotrophic factor (BDNF), glial cell line-derived neurotrophic factor GDNF, Vascular endothelial growth factor (VEGF), pigment epithelium-derived factor (PEDF), fibroblast growth factor (FGF), the cerebral dopamine neurotrophic factor (CDNF)/mesencephalic astrocyte-derived neurotrophic factor (MANF) family, the neurokines, neurturin, neurotrophin 3 (NT3), neurotrophin 4 (NT4), and neurotrophin 5 (NT5). Each binds to one member of the tyrosine receptor kinase (Trk) family: NGF binds to TrkA, BDNF and NT4 bind to TrkB, and NT3 binds to TrkC [49]-[53]. GDNF and neurturin (NTN) are the two main members of the family ligands (GFLs). GDNF signaling is mediated via a multicomponent receptor complex consisting of a binding receptor (GDNF family receptor alpha, GFR $\alpha$ ) and a second receptor called Ret receptor tyrosine kinase [54]. There are numerous neurotrophic factors have been advanced and are under investigation to treat Parkinson's disease among them some are described below.

\subsection{NGF}

Nerve growth factor (NGF) is the first member of the neurotrophin family, which was discovered in the 1950s, was first applied in the sensory and autonomic nervous system, then in central nervous, endocrine and immune systems. NGF exerts its biological action by challenging the specific receptor tropomyosin kinase receptor A (TrkA), which is a typical tyrosine kinase receptor that influence a number of neuronal functions, including cell survival and axonal growth [55] [56].

\subsection{BDNF}

Brain-derived neurotrophic factor (BDNF) belongs to a family of related proteins known as neurotrophins, which acts through the tropomyosin-related kinase B (trkB) receptor and transduces intracellular signalling events that are critical for axonal growth, neuronal survival and plasticity in the adult brain which is important for the normal development of the central and peripheral nervous systems [57]. A reduction in BDNF expression is associated with neurodegenerative diseases such as Parkinson's disease, Alzheimer's disease and dementia with Lewy bodies [58]. A decreased level of BDNF mRNA and protein expression has been consistently reported in multiple brain areas of AD postmortem and in the substantianigra pars compacta, caudate nucleus and putamen of PD patients [59]. Many studies have shown that the rehabilitation treatment increases the BDNF levels and may decrease the risk of PD in humans, reduce PD symptoms in animal models and improves PD signs in patients in the early stages of the disease [60] [61]. A recent pilot study on the effect of cognitive training on BDNF serum levels in individuals with Parkinson's disease showed that PD patients undergoing the cognitive rehabilitation, besides improving their cognitive performance as measured by the Zoo Map Test, also displayed increased serum BDNF levels as compared to the placebo group. These findings suggested that BDNF serum levels may represent a biomarker of the effects of cognitive rehabilitation in PD patients affected by mild cognitive deficits (MCI) [62].

\subsection{GDNF}

The glial cell line-derived neurotrophic factor (GDNF) is a well-established trophic agent for dopaminergic (DA) neurons in vitro and in vivo. Four different ligand-receptor binding pairs of the GDNF family exist in mammals, and they all signal via the transmembrane RET receptor tyrosine kinase and GRAL (GDNF Receptor AlphaLike) protein of unknown function and Gas1 (growth arrest specific 1) have GDNF family receptor (GFR)-like domains [63]. GDNF is necessary for the maintenance of neuronal morphological and neurochemical phenotype and protects DA neurons from toxic damage. However, the mechanism of the GDNF for the neroprotective effect is still unclear [64]. GDNF and its receptor GFR $\alpha 1$ have been implicated in the survival of ventral midbrain 
dopaminergic (DA) neurons, but the molecular mechanisms by which GDNF generates DA neurons in grafted midbrain-derived neural stem cells (mNSCs) are not fully understood [65]. Preclinical studies indicate that members of the glial cell line-derived neurotrophic factor family of ligands are capable of preserving the degenerating dopamine neurons [66]. GDNF does not cross the blood-brain barrier, thus direct injections of high doses of recombinant glial cell line-derived neurotrophic factor have been shown to protect adult nigral dopaminergic neurons [67].

To assess the neurotrophic and neuroprotective effect of GDNF in the unilateral 6-hydroxydopamine (6OHDA) model of PDand in normal rats, GDNF was administered by the intranasal route. In the first study, rats were received single intranasal doses of 50- $\mu \mathrm{g}$ GDNF in phosphate-buffered saline (PBS) or cationic liposomes, but no 6-OHDA. In the second study, rats were nasally administered 10, 50 or $150 \mu \mathrm{g}$ of GDNF in PBS or cationic liposomes $1 \mathrm{~h}$ before injection of 6-OHDA. All groups were evaluated 3 - 4 weeks later and it was found that both intranasal GDNF treatments induced a neurotrophic effect in the SN insofar as the number of tyrosine hydroxylase (TH)-positive neurons was significantly higher than in controls given intranasal PBS liposomes. Thus, these results have shown that both neurotrophic effects of intranasal GDNF in the intact SN as well as neuroprotective efficacy in the unilateral 6-OHDA model, support as a potential approach for the treatment of PD [68].

\subsection{VEGF}

The polypeptide known as VEGF was first isolated in 1983 by Harold Dvorak and his colleagues, and was initially identified as vascular permeability factor (VPF) on account of its ability to induce vascular leakage. The VEGF family is comprised of five main members, namely VEGF-A, VEGF-B, VEGF-C, VEGF-D, and PLGF (placental growth factor) [69]. However, VEGF-B, C, D, and PLGF serve various physiological roles, VEGF-A is generally regarded as the most biologically relevant members of the VEGF family. The VEGF family is known to bind three different receptor tyrosine kinases (RTKs). VEGF-A is known to bind two similar receptor RTKs, VEGFR1.VEGF-B binds to VEGFR1 only, whereas the other isoforms of VEGF are known to bind to VEGFR2 and VEGFR3 [70]. Vascular endothelial growth factor (VEGF or VEGF-A) is a hypoxia induced angiogenic growth factor that is potent in neurotrophy, neuroprotection, anti-apoptosis and cell proliferation. Recent reports suggest that VEGF is related to many central nervous system diseases, such as cerebral ischemic disease, Alzheimer's disease and Parkinson's disease [71]. Reduced levels of VEGF, which is a well-known angiogenic molecule and its receptor activity is strongly controlled by endocytosis, which can terminate or enhance signal transduction in the angiogenic endothelium might cause neurodegeneration in part by impairing neural tissue perfusion, vasoregulation and normal functioning of perivascular autonomic nerves. Additionally, VEGF has been reported to support neuroprotection in dopaminergic neurons by indirect and direct mechanisms and suppress apoptosis in dopaminergic neurons in vitro, but the exact molecular regulation of these processes remains incompletely understood [72].

In the current study, for the evaluation of neuroprotective potential for PD by testing an expanded dose range of VEGF-B (1 and $10 \mu \mathrm{g}$ ) and directly comparing both neuroprotective and neurorestorative effects of VEGF-B in progressive unilateral 6-hydroxydopamine (6-OHDA) PD models to a single dose of glial cell line-derived neurotrophic factor (GDNF, $10 \mu \mathrm{g}$ ), that has been established by several groups as a standard in both preclinical PD models. Both doses of VEGF-B caused an increase in tyrosine hydroxylase (TH)-positive cell and fiber count in the substantia nigra (SN) and striatum in the neuroprotective experiment and no significant adverse events were reported. Thus, the authors have suggested that VEGF-B has potential as a neuroprotective agent for PD therapy and should be further investigated [73].

\subsection{FGF}

The fibroblast growth factor (FGF) family comprises 22 members with diverse functions in development and metabolism. Fibroblast growth factor 20 (FGF20) widely expressed in the substantia nigra is a neurotrophic factor and enhances the survival of mid brain dopaminergic neurons [74]. Seven FGFs have been associated with human disorders. These include FGF3 in Michel aplasia; FGF8 in cleft lip/palate and in hypogonadotropic hypogonadism; FGF9 in carcinoma; FGF10 in the lacrimal/salivary gland aplasia, and lacrimo-auriculo-dento-digital syndrome; FGF14 in spinocerebellar ataxia; FGF20 in Parkinson disease; and FGF23 in tumoral cal- 
cinosis and hypophosphatemic rickets [75]. The fibroblast growth factor-20 (FGF-20) has been shown to protect dopaminergic neurons against a range of toxic insults in vitro, through the activation of fibroblast growth factor receptor 1 (FGFR1) [76].

For the study, FGF-20 was administered in the unilateral, 6-OHDA lesion rat model of PD and the study was demonstrated that, in embryonic ventral mesencephalic (VM) cultures, FGFR1 was expressed on tyrosine hydroxylase (TH)-positive neurons in the substantia nigra pars compacta (SNpc) of native adult rat brain. Thus, the study was suggested that FGF-20 play an important role to preserve dopamine neuron integrity and some aspects of motor functions in a rodent model of PD and can imply as a potential neuroprotective for FGF-20 for the treatment of PD [77].

\subsection{CDNF}

Cerebral Dopamine Neurotrophic Factor (CDNF) and Mesencephalic Astrocyte-derived Neurotrophic Factor (MANF) are members of a recently discovered family of neurotrophic factors (NTFs). The main distinguishing feature of this family is that the members (CDNF and MANF) contain eight cysteine residues that were conserved in evolution from invertebrates to vertebrates [78]. CDNF and MANF consist of two domains; an amino-terminal saposin-like domain that may interact with lipids or membranes, and a presumably unfolded carboxy-terminal domain that may protect cells against endoplasmic reticulum stress [79]. CDNF and MANF protect midbrain dopaminergic neurons and restore motor function in 6-hydroxydopamine rat model of PD in vivo. However, the molecular function of CDNF in PD remains unclear [80].

One study was conducted in primary glial cell cultures to see the anti-inflammatory effect of the CDNF both in vivo and in 6-hydroxydopamine (6-OHDA) models of Parkinson's disease by introducing intranigral transfection of the human CDNF (hCDNF) gene in the critical period of inflammation after a single intrastriatal injection in the rat, it was found that the overexpression of CDNF reduced nitrosative stress, glial markers and IL-6 levels in the SN, but not TNF- $\alpha$ and IL-1 $\beta$ levels. Thus, the authors suggested that the possible participation of TNF- $\alpha$, IL-1 $\beta$ and IL-6 in rCDNF production by astrocytes, supporting their anti-inflammatory role [81] [82].

\subsection{Neurturin}

Glial cell line-derived neurotrophic factor (GDNF) or its naturally occurring analogue, neurturin (NTN), can potentially improve the function and delay the rate of degeneration of dopaminergic neurons in Parkinson's disease [83]. The current data demonstrated that delivering NRTN directly to the SN: 1) expands NRTN distribution within the terminal field and cell bodies of targeted nigrostriatal neurons, 2) enhances intracellular neurotrophic factor signaling in the nigrostriatal neurons, and 3) produce greater numbers of surviving dopamine neurons against 6-OHDA-induced toxicity, particularly under the conditions of active axonopathy [84].

For the study, an open-label phase I, clinical trial study was conducted in the USA with 12 patients aged 35 - 75 years with a diagnosis of PD for at least 5 years in accordance with the UK Brain Bank Criteria received bilateral, stereotactic, intraputaminal injections of adeno-associated virus serotype 2-neurturin (CERE-120). The first six patients received doses of $1.3 \times 10(11)$ vector genomes $(\mathrm{vg}) /$ patient, and the next six patients received $5.4 \times 10$ (11) vg/patient and it was demonstrated that the gene therapy was safe, well tolerated and no any adverse events were reported. It showed that improvement in motor function with sub score of the Unified Parkinson's Disease Rating Scale (UPDRS) of 14 points (SD 8; $p=0.000121$ [36\% mean increase; $p=0.000123$ ]) and a mean increase of $2.3 \mathrm{~h}(2 ; 25 \%$ group mean increase; $p=0.0250)$ in on time without troublesome dyskinesia were seen. Thus, the authors suggested that the initial data support the safety, tolerability, and potential efficacy of CERE-120 as a possible treatment for PD [85].

Another, a double-blind, phase 2 randomized clinical trials were conducted in the USA with 58 patients between December, 2006, and November, 2008. For the study, AAV2-neurturin $\left(5 \cdot 4 \times 10^{11}\right.$ vector genomes) was injected bilaterally into the putamen or sham surgery in the trial. The result showed that there was no significant difference in the primary endpoint in patients treated with AAV2-neurturin compared with control individuals. Serious adverse events occurred in 13 of 38 patients treated with AAV2-neurturin and four of 20 control individuals. Three patients in the AAV2-neurturin group and two in the sham surgery group developed tumors. The authors suggested that intraputaminal AAV2-neurturin is not superior to sham surgery when assessed using the 
UPDRS motor score at 12 months. However, the possibility of a benefit with additional targeting of the substantia nigra and longer term follow-up should be investigated in further studies [86].

\subsection{Indications of Neurotrophic Factors}

1. NTFs are commonly used in the treatment of neurological disorders, including the most common central neurodegenerative diseases, Alzheimer's disease and Parkinson's disease.

2. This approach may also prove effective for the peripheral nerve injury, which is a serious issue affecting $2.8 \%$ of trauma patients and many of whom will be subjected to lifelong disability.

3. NTFs also play an important role in the development of potential neuroprotective glaucoma and hearing disorder treatments.

\subsection{Limitations of Use}

Despite their obvious attractiveness as therapeutic agents, they have some serious restrictions in clinical use. The most limiting of these are their short biological half-life and vulnerability to structural disruption or modification, leading to loss of bioactivity [87].

\section{Deep Brain Stimulation (DBS)}

Deep brain stimulation (DBS) has developed over the past two decades and still in developing phase as an effective therapeutic option for various neurological and psychiatric disorders [88]. The Subthalamic nucleus (STN), the internal segment of the Globus pallidus (Gpi), and thalamus are the standard DBS targets for the treatment of advanced Parkinson's disease, the tremor or rigidity and bradykinesia [89] [90]. The Food and Drug Administration (FDA) has approved that DBS is safe, well tolerated, and effective for the treatment of advanced Parkinson's disease (PD), essential tremor (ET), obsessive compulsive disorder (OCD), and for dystonia [91] [92]. DBS involves the delivery of particular electrical signals to the specific deep anatomical structures of the central nervous system with the objective of altering or modulating neural functioning and achieving a reversible, adjustable and therapeutic or clinically beneficial effect [93]. However, the exact mechanism of action of DBS is still under investigations, some authors suggested that DBS of the basal ganglia improves cortical function by alleviating excessive beta phase locking of motor cortex neurons [94] [95].

A large meta-analysis comparing deep brain stimulation of the Globus pallidus and Subthalamic nucleus to treat advanced Parkinson's disease, was conducted for the better response in patient who underwent STN DBS Vs those who underwent GPi DBS and was demonstrated that deep brain stimulation of the Gpi or STN equally improved motor function, measured by the Unified Parkinson's Disease Rating Scale Section III (UPDRSIII) (motor section, for patients in on- and off-medication phases), within 1 year post surgery and there was no any differences in therapeutic efficacy for PD [96]-[98].

\subsection{Indications OF DBS}

1. The commonest clinical indications for DBS are PD, dystonia and essential tremor.

2. Other indications for DBS are neuropsychiatric and neurodegenerative disorders such as Tourette syndrome, depression, obsessive compulsive disorder (OCD), epilepsy, intractable pain, camptocormia, headache, restless legs syndrome, and Alzheimer disease.

3. Deep brain stimulation of subthalamic nucleus (STN-DBS) is currently the most common therapeutic surgical treatment for patients with PD with motor fluctuations and/or dyskinesias and that are not adequately controlled with advanced medical therapy or with medication-refractory tremor [99]-[101].

\subsection{Contraindications (Relative)}

1) Biological age over 75 years

2) Severe/malignant comorbidity with considerably reduced life-expectancy

3) Chronic immunosuppression

4) Distinct brain atrophy

5) Severe psychiatric disorder (cognitive deficits/dementia, frontal-dysexecutive syndrome, manifest psycho- 
sis, depression, substance abuse, personality disorder) [102].

\subsection{Complications and Adverse Effects of DBS}

Adverse effects of DBS consist of a wide variety of acute or chronic neurological and neuropsychological complications such as those related to surgery, hardware and stimulation.

1. The most severe complication of DBS surgery is an intracerebral hemorrhage (ICH) which is reported to occur in $0.2 \%$ - $5 \%$ with symptomatic hemorrhage occurring in $2.1 \%$ of patients and hemorrhage resulting in permanent neurological deficit or death in $1.1 \%$.

2. Postoperative seizures have also been reported and generally occur within $48 \mathrm{~h}$ of surgery, with an estimated incidence of $2.4 \%$.

3. The most common hardware complications include postoperative infections, ranging from $1.8 \%-15.2 \%$ of cases is reported and other complications are electrode migrations or misplacements, wire fractures, skin erosion and device malfunction. Infections are the most reported hardware complications.

4. Stimulation-related adverse effects include muscle contractions, dysarthria, ocular deviations, dyskinesia, cognitive disturbances, headache, and affective disturbances such as mania [103] [104].

\section{Stem Cell Therapy}

Over the past two decades, stem cell technologies have become an increasingly attractive therapeutic option to investigate and treat neurodegenerative diseases [105]. Stem cells are divided into two groups: embryonic and adult stem cells. In another categorization stem cells are divided to Totipotent, Multipotent and Unipotentcells [106]. Naturally occurring stem cells generally include embryonic stem cells (ESCs), fetal stem cells (FSCs), and adult stem cells [107]. Various stem cell therapies are under investigations and have been developed to treat neurodegenerative diseases, among them embryonic stem cells (ESCs), mesenchymal stem cells (MSCs), neural stem cells (NSCs) and induced pluripotent stem cells (iPSCs) are the most common tools that hold a great promise for regeneration of the brain [108]. Dopaminergic (DA) neurons in the substantia nigra pars compacta (also known as A9 DA neurons) are the specific cell type that is lost in PD. During neural development, A9 DA neurons originate from the floor plate (FP) precursors located at the ventral midline of the central nervous system which is essential for the embryonic DA neuron development [109] [110]. Stem cell-based therapies can be beneficial by acting through several mechanisms such as cell replacement, trophic actions, mediating remyelination and modulation of inflammation [111] [112].

The 1-methyl-4-phenyl-1,2,3,6-tetrahydropyridine (MPTP) animal model is a useful tool to study PD and was used in the present study to investigate the potential benefits as well as the deleterious effects of systemic bone-marrow mononuclear cell (BMMC) or mesenchymal stem cell (BM-MSC) transplantation. MPTP administration was resulted in a breakdown of the blood-brain barrier and motor impairment in the open field test $24 \mathrm{~h}$ after surgery. However, systemic BM-MSC transplantation that reaches the injury site and prevents neuronal damage after an MPTP infusion could be considered as a potential treatment for PD during the early stage of disease development. The study was demonstrated that caution should be taken when considering cell therapy using BMMCs to treat PD [113]. Another study was conducted by generating iPS cell-derived NSC transplant into the striatum of the 6-hydroxydopamine (OHDA)-induced PD rats and was identified that it improved their functional defects of rotational asymmetry at 4, 8, 12 and 16 weeks after transplantation. IPS cell-derived NSCs were found to survive and integrate into the brain of transplanted PD rats and differentiated into neurons, including dopamine neurons in vivo. Thus, the authors suggested that transplantation of iPS cell-derived NSCs has therapeutic potential for PD [114]. Animal studies have further shown that iPS cells from fibroblasts could be induced into dopamine neurons and transplantation of these cells within the central nervous system improved motor symptoms in the 6-OHDA model of PD [115].

\subsection{Indications of Stem Cell Therapy}

1. Stem cell therapy is a newer technology and is indicated in patients who are unresponsive to pharmacological therapy, neurosurgical procedures (e.g. pallidotomy, thalamotomy or DBS).

2. It is promising therapy for many diseases such as Parkinson's disease, Alzheimer's disease, Amyotrophic lateral sclerosis (ALS), Huntington's disease (HD), Stroke, Spinal Cord Injury, Multiple Sclerosis, Friedreich's 
ataxia, Machado-Joseph disease, Pelizaeus-Merzbacher disease, fragile X-syndrome, familial dysautonomia (FD), spinobulbar muscular atrophy, schizophrenia, Dravet's syndrome of intractable epilepsy, Radiation Induced Intestinal Injury, Inflammatory Bowel Disease, Liver Disease, Duchenne Muscular Dystrophy, Diabetes, Heart Disease, Bone Disease, ophthalmic, Renal Disease, Chronic Wounds, Graft-Versus-Host Disease, Sepsis and Respiratory diseases.

3. It has also potential role in various hemoto-oncology diseases such as lymphoblastic leukemia, multiple myeloma, thalassemia etc. [116]-[118].

\subsection{Risks and Limitations of Use}

1. The physical, chemical, and electrical state of the stem cell niche will have profound influences on stem cell function. Alterations of the stem cell niche in diseases such as diabetes will decrease the ability of endogenous stem cells, or autologous administered stem cells, to increase neovascularization and promote wound healing.

2. Pluripotent stem cell-derived cell populations pose a risk for tumor formation after transplantation.

3. Post-transplantation abnormal dyskinetic movements-graft-induced dyskinesias (GID) have been reported in all the different clinical trials.

4. There are limitations associated with this approach, including high tissue variability, lack of scalability, ethical concerns, inability to obtain an epidemiologically meaningful quantity of tissue [119]-[121].

\section{Gene Therapy for Parkinson's Disease}

Over the past two decades, gene based therapeutic strategy have been advanced to treat neurodegenerative disorders via viral or non-viral vectors which is regulated by the introduction of exogenous nucleic acids such as DNA, mRNA, small interfering RNA (siRNA), microRNA (miRNA) or antisense oligonucleotides [122]. Various non-viral vectors have been developed to provide a safer approach for gene delivery, including polymers, peptides, liposomes, and nanoparticles [123]. Due to the short duration of gene expression, nonviral techniques are insignificantly used for the treatment of chronic neurodegenerative disorders such as PD. viral vectors, derived from either DNA or RNA are most commonly used method for the modulation of gene transfer in the CNS, with the potential to cause long lasting gene expression via episome formation or DNA integration into the host genome [124]. Currently, there are various viral vectors have developed to transfer foreign gene, based on the criterion of safety, stability of gene expression and transduction of specific cellular targets, only recombinant adeno-associated virus (rAAV) and lentivirus vectors are most commonly used in clinical trials for PD, which are focused on three therapeutic approaches; augmentation of dopamine levels via increased neurotransmitter production, modulation of the neuronal phenotype and neuroprotection [125] [126]. Over the past decade, nine gene therapy clinical trials for PD have been investigated such as AAV2/AADC, AAV2/ GAD, a combination of GAD-65 and GAD-67, AAV2/NRTN, LENTI/AADC-TH-CH1, AAV2/GDNF, Synopsis and ProSavin [127] [128].

\subsection{Indications of Gene Therapy}

1. Treatment of various central nervous system (CNS) disorders such as Parkinson's disease, Alzheimer's disease, Motor neuron disease (e.g. ALS), Canavan disease, Batten disease, adrenoleukodystrophy (ALD), lysosomal storage disease, Mucopolysaccharidosis IIIB and Krabbe disease.

2. Other indications of gene therapy are neurodevelopmental disorders, such as Rett Syndrome, Fragile X, and autism.

3. Gene therapy is a promising therapy for various cerebrovascular diseases, including ischemic stroke, hemorrhagic stroke and subarachnoid hemorrhage (SAH).

4. Recently it is also used in the several haemoglobinopathies, such as beta-thalassaemia, sickle cell disease and Fanconi anemia,

5. Gene therapy is also used in the various immunodeficiency conditions, including X-linked severe combined immunodeficiency (SCID-X1), adenosine deaminase deficiency (ADA-SCID), chronic granulomatous disease (CGD), and Wiskott-Aldrich syndrome (WAS). [129]-[133].

The following gene therapies are in clinical trials for the treatment of PD. 


\subsection{AADC (Aromatic L-Amino Acid Decarboxylase)}

In Parkinson's disease, there is marked degeneration of nigrostrial neurons, which causes progressive loss of aromatic l-amino acid decarboxylase (AADC), the enzyme that converts levodopa into dopamine [134]. Several Phase Istudies have undertaken in primate models of PD with intrastriatal infusion of an adeno-associated viral type 2 vector (AAV-2) containing the human aromatic l-amino acid decarboxylase (AAV-hAADC) gene resulted in robust gene expression without the side effects associated with higher doses and these studies have demonstrated that the gene therapy was well tolerated and with higher doses of adeno-associated viral vector containing the human aromatic l-amino acid decarboxylase gene increase dopamine production in the putamen and provide more profound clinical benefit. Thus, the authors suggested that bilateral intrastriatal infusion of adeno-associated viral type 2 vector containing the humanAADC gene improves mean scores on the Unified Parkinson's Disease Rating Scale by approximately 30\% in the on and off states, but the surgical procedure may be associated with an increased risk of intracranial hemorrhage and self-limited headache [135] [136].

\subsection{GAD (Glutamic Acid Decarboxylase)}

Gene transfers of glutamic acid decarboxylase (GAD) and other methods that modulation of excitatory and inhibitory activity of GABA in the subthalamic nucleus and improves basal ganglia function in Parkinsonian animal models [137].

For the study, an open label, phase I trial study was evaluated with administration of a unilateral injection of AAV-GAD into the subthalamic nucleus of patients with Parkinson's disease with low-dose, four medium-dose, and four high-dose AAV-GAD at New York Presbyterian Hospital and the study was identified that there were no adverse events related to gene therapy and there was significant improvement in motor UPDRS scores $(p=$ 0.0015), predominantly on the side of the body that was contralateral to surgery, were seen 3 months after gene therapy and persisted up to 12 months. These results demonstrated that AAV-GAD gene therapy of the subthalamic nucleus is safe and well tolerated by patients with advanced Parkinson's disease, and suggesting that invivo gene therapy in the adult brain might be safe for various neurodegenerative diseases [138].

Another, a double-blind, phase 2, randomized controlled trial was undertaken in seven places in the USA between Nov 17, 2008, and May 11, 2010 aimed to assess the effect of bilateral delivery of AAV2-GAD in the subthalamic nucleus compared with sham surgery in patients with advanced Parkinson's disease. The AAV2GAD group showed a significantly greater improvement from baseline in UPDRS scores compared with the sham group over the 6-months course of the study (RMANOVA, $p=0.04$ ) and there were no serious adverse effects were found, the most common were headache and nausea. These studies have demonstrated that the efficacy and safety of bilateral infusion of AAV2-GAD in the subthalamic nucleus support its further development for Parkinson's disease and shows the promise of gene therapy for neurological disorders [139].

\subsection{AADC, GCH-1, and TH}

All studies have utilized a mix of two monocistronic vectors expressing either of the two genes, tyrosine hydroxylase (TH) and GTP cyclohydrolase-1 (GCH1), needed for DOPA production. TH converts tyrosine to L-3, 4-dihydroxyphenylalanine (L-DOPA), GCH1 is a key enzyme in the synthesis of the cofactor 5, 6, 7, 8-tetrahydroL-biopterin (BH4). Together, TH and GCH1 are the rate-limiting enzymes in the production of DOPA from the dietary amino acid tyrosine. DOPA is then converted into DA by the aromatic L-amino acid decarboxylase (AADC) and a vesicular monoamine transporter (VMAT-2) transports dopamine into synaptic vesicles, thereby supporting regulated, the vesicular release of dopamine and relieving feedback inhibition of TH by dopamine [140]-[142].

For the study, the PD rat model was used for the in vivo gene therapy of a recombinant adeno-associated virus (AAV2) containing a human glutamic acid decarboxylase 65 (rAAV2-hGAD65) gene delivered to the subthalamic nucleus (STN). This is combined with the ex vivo gene delivery of TH by fibroblasts injected into the striatum. After the treatment, the study was demonstrated that rotation behavior was improved with the greatest efficacy in the combination group. The authors suggested that subthalamic hGAD65 gene therapy and combined with TH gene therapy can alleviate symptoms of the PD model rats, independent of the protection the DA neurons from death [143]. 


\subsection{ProSavin}

ProSavin is a newer approach to gene therapy for PD and has shown promising results in a phase 1/2 study. ProSavin gene therapy for PD is under investigation [144]. It is generated from the producer cell lines (PCLs) performs comparably in vivo to that produced by the standard transient transfection process with respect to transduction efficiency and immunogenicity [145].

A phase 1/2 open-label clinical trial with 12-month follow-up at two study sites (France and UK) to assess the safety and efficacy of ProSavin were conducted and for this study bilateral injection of ProSavin was administered into the putamen of patients with PD to assess the safety, tolerability, and efficacy of bilateral, intrastriatal delivery of ProSavin, a lentiviral vector-based gene therapy aimed at restoring local and continuous dopamine production in patients with advanced PD. For the study, 15 patients received ProSavin under general anesthesia and were followed up (three at low dose, six mid dose, and six high doses). During the first 12 months of follow-up, 54 drug-related adverse events were reported (51 mild, three moderate). Most common adverse events increased on-medication dyskinesias (20 events, 11 patients) and on-off phenomena (12 events, nine patients) were noted. No serious adverse events related to the study drug or surgical procedures were reported. The authors suggested that ProSavin was safe and well tolerated in patients with advanced PD and improvement in motor symptoms were observed in all patients [146].

\section{Conclusion}

In summary, till date, the treatment for PD remains essentially symptomatic although this approach is simple and effective during the early phases of the disease. The management of advanced PD is complicated due to the decline in the number of dopaminergic neurons, the development of motor complications, and the appearance of non-dopaminergic motor and non-motor features, resulting in significant morbidity and a shortened lifespan. There are various therapeutic strategies have been advanced for the treatment of PD, including pharmacotherapy such as dopaminergic and non-dopaminergic therapies, anti-inflammatories, neurotrophic factors, DBS, cell based therapies and gene therapies. But all of these newer treatments have merits and demerits. Neurotrophic factors are one particularly promising therapeutic and potentially neuroprotective approach. However, severe delivery obstacles have limited their application in PD treatment. Surgical treatment is becoming more common for PD because of advances in brain imaging and neurosurgical techniques. DBS of the subthalamic nucleus effectively improves motor function and reduces motor fluctuations, dyskinesia, and antiparkinsonian medication effects, but the treatment is expensive, and cannot cure disease. In the past 20 years, great progress was made in stem cell technology. The rapidly advancing stem cell field is providing attractive options for fighting PD disease and other neurodegenerative disorders. The main limitations of transplantation are the ethical, practical and safety issues and allogeneic transplantation immune rejection problem. PD is the central nervous system degenerative disease of choice for gene therapy. This is because the basic pathological change is clear, related genes have been cloned and have appropriate animal models, the anatomical position clears to facilitate stereotaxic injection. Therefore, PD gene therapy has made a lot of progress in recent years. But gene therapy is still not mature. There are many problems to be solved, such as the purpose of looking for more valuable genes, the mechanism of gene expression form has a sequence of genes, build tissue specificity or directional gene expression vector and overcome the virus vector immune response. We have found that there is no permanent cure for neurodegenerative disorders and for the majority of conditions, the etiological factors are unknown. Therefore, most therapies are oriented toward symptomatic relief aiming to slow or even terminate neurodegeneration. Hence, we suggest for the cure of neurodegenerative disorder need further research to develop a newer approach as a novel therapy for Parkinson's disease.

\section{Acknowledgements}

I would like to express my sincere gratitude to my advisor Prof. Dr. Li Yun for the continuous support, patience, motivation, and immense knowledge. Her guidance helped me in all the time of research and writing of this article. Without her precious support it would not be possible to write my article.

\section{References}

[1] Monti, C., Bondi, H., Urbani, A., Fasano, M. and Alberio, T. (2015) Systems Biology Analysis of the Proteomic Alte- 
rations Induced by MPP(+), a Parkinson’s Disease-Related Mitochondrial Toxin. Frontiers in Cellular Neuroscience, 9 , 14. http://dx.doi.org/10.3389/fncel.2015.00014

[2] Dyson, S.C. and Barker, R.A. (2011) Cell-Based Therapies for Parkinson's Disease. Expert Review of Neurotherapeutics, 6, 831-844. http://dx.doi.org/10.1586/ern.11.33

[3] Schapira, A.H. (2013) Recent Developments in Biomarkers in Parkinson Disease. Current Opinion in Neurology, 4, 395-400. http://dx.doi.org/10.1097/WCO.0b013e3283633741

[4] Uversky, V.N. and Eliezer, D. (2009) Biophysics of Parkinson’s Disease: Structure and Aggregation of Alpha-Synuclein. Current Protein \& Peptide Science, 5, 483-499. http://dx.doi.org/10.2174/138920309789351921

[5] Ma, L., Wei, L., Wu, F., et al. (2013) Advances with microRNA in Parkinson's Disease Research. Drug, Design, Development and Therapy, 7, 1103-1113.

[6] McGhee, D.J., Royle, P.L., Thompson, P.A., et al. (2013) A Systemic Review of Biomarkers for Disease Progression in Parkinson's Disease. BMC Neurology, 13, 35. http://dx.doi.org/10.1186/1471-2377-13-35

[7] Feng, L.R. and Manguirs-Zeiss, K.A. (2010) Gene Therapy in Parkinson’s Disease: Rationale and Current Status. CNS Drugs, 3, 177-192. http://dx.doi.org/10.2165/11533740-000000000-00000

[8] Zhang, L., Ding, H., Wang, D.H., et al. (2013) Calpastatin Gene (CAST) Is Not Associated with Late Onset Sporadic Parkinson's Disease in the Han Chinese Population. PLoS One, 8, e70935. http://dx.doi.org/10.1371/journal.pone.0070935

[9] Gazewood, J.D., Richards, D.R. and Clebak, K. (2013) Parkinson Disease: An Update. American Family Physician, 87, 267-273.

[10] Chin-Chan, M., Navarro-Yepes, J. and Quintanilla-Vega, B. (2015) Environmental Pollutants as Risk Factors for Neurodegenerative Disorders: Alzheimer and Parkinson Diseases. Frontiers in Cellular Neuroscience, 10, 124.

[11] Baltazar, M.T., Dinis-Oliveira, R.J., de Lourdes Bastos, M., et al. (2014) Pesticides Exposure as Etiological Factors of Parkinson's Disease and Other Neurodegenerative Diseases-A Mechanistic Approach. Toxicology Letters, 230, 85103. http://dx.doi.org/10.1016/j.toxlet.2014.01.039

[12] Nuytemans, K., Theuns, J., Cruts, M. and Van Broeckhoven, C. (2010) Genetic Etiology of Parkinson Disease Associated with Mutations in the SNCA, PARK2, PINK1, PARK7, and LRRK2 Genes: A Mutation Update. Human Mutation, 7, 763-680. http://dx.doi.org/10.1002/humu.21277

[13] Bonifati, V. (2014) Genetics of Parkinson's Disease-State of the Art, 2013. Parkinsonism \& Related Disorders, 20, S23-S28. http://dx.doi.org/10.1016/S1353-8020(13)70009-9

[14] Kieburtz, K. and Wunderle, K.B. (2013) Parkinson’s Disease: Evidence for Environmental Risk Factors. Movement Disorders, 1, 8-13.

[15] Massano, J. and Bhatia, K.P. (2012) Clinical Approach to Parkinson's Disease: Features, Diagnosis, and Principles of Management. Cold Spring Harbor Perspectives in Medicine, 6, a008870.

[16] Maass, A. and Reichmann, H. (2013) Sleep and Non-Motor Symptoms in Parkinson’s Disease. Journal of Neural Transmission, 120, 565-569. http://dx.doi.org/10.1007/s00702-013-0966-4

[17] Lima, M.M., Martins, E.F., Delattre, A.M., et al. (2012) Motor and Non-Motor Features of Parkinson's Disease-A Review of Clinical and Experimental Studies. CNS \& Neurological Disorders Drug Targets, 11, 439-449.

[18] Gallegos, S., Pacheco, C., Peters, C., Opazo, C.M. and Aguayo, L.G. (2015) Features of Alpha-Synuclein That Could Explain the Progression and Irreversibility of Parkinson's Disease. Frontiers in Neuroscience, 9, 59.

[19] Weintraub, D. and Burn, D.J. (2011) Parkinson's Disease: The Quintessential Neuropsychiatric Disorder. Movement Disorders, 6, 1022-1031.

[20] Breydo, L., Wu, J.W. and Uversky, V.N. (2012) A-Synuclein Misfolding and Parkinson’s Disease. Biochimica et Biophysica Acta, 1822, 261-285.

[21] Miklya, I., Pencz, N., Hafenscher, F. and Göltl, P. (2014) The Role of Alpha-Synuclein in Parkinson’s Disease. Neuropsychopharmacol Hung, 2, 77-84.

[22] Olanow, C.W. and Brundin, P. (2013) Parkinson’s Disease and Alpha Synuclein: Is Parkinson’s Disease a Prion-Like Disorder? Movement Disorders, 1, 31-40.

[23] Gad Elhak, S.A., Ghanem, A.A., Abdelghaffar, H.E., Dakroury, S. and Salama, M.M. (2010) Parkinson’s Disease: Is It a Toxic Syndrome? Neurology Research International, 2010, Article ID: 103094.

[24] Tew, E.H., Naismith, S.L., Pereira, M. and Lewis, S.J. (2013) Quality of Life in Parkinson's Disease Caregivers: The Contribution of Personality Traits. BioMed Research International, 2013, Article ID: 151872.

[25] Menon, B., Nayar, R., Kumar, S., et al. (2015) Parkinson’s Disease, Depression, and Quality-of-Life. Indian Journal of Psychological Medicine, 37, 144-148. http://dx.doi.org/10.4103/0253-7176.155611 
[26] Leroi, I., Andrews, M., McDonald, K., et al. (2012) Apathy and Impulse Control Disorders in Parkinson’s Disease: A Direct Comparison. Parkinsonism \& Related Disorders, 2, 198-203. http://dx.doi.org/10.1016/j.parkreldis.2011.10.005

[27] Leroi, I., Harbishettar, V., Andrews, M., et al. (2012) Carer Burden in Apathy and Impulse Control Disorders in Parkinson's Disease. International Journal of Geriatric Psychiatry, 2, 160-166.

[28] Denyer, R. and Douglas, M.R. (2012) Gene Therapy for Parkinson’s Disease. Parkinson's Disease, 2012, Article ID: 757305. http://dx.doi.org/10.1155/2012/757305

[29] Hickey, P. and Stacy, M. (2011) Available and Emerging Treatments for Parkinson's Disease: A Review. Journal of Drug Design, Development and Therapy, 5, 241-254.

[30] Bargiotas, P. and Konitsiotis, S. (2013) Levodopa-Induced Dyskinesias in Parkinson’s Disease: Emerging Treatments. Journal of Neuropsychiatric Disease and Treatment, 9, 1605-1617.

[31] Chaudhuri, K.R., Rizos, A. and Sethi, K.D. (2013) Motor and Nonmotor Complications in Parkinson's Disease: An Argument for Continuous Drug Delivery? Journal of Neural Transmission, 120, 1305-1320.

[32] Qian, L., Flood, P.M. and Hong, J.S. (2010) Neuroinflammation Is a Key Player in Parkinson's Disease and a Prime Target for Therapy. Journal of Neural Transmission, 7, 971-979.

[33] Niranjan, R. (2014) The Role of Inflammatory and Oxidative Stress Mechanisms in the Pathogenesis of Parkinson’s Disease: Focus on Astrocytes. Molecular Neurobiology, 49, 28-38.

[34] Aguirre-Vidal, Y., Montes, S. and Tristan-López, L. (2015) The Neuroprotective Effect of Lovastatin on MPP ${ }^{+}$-Induced Neurotoxicity Is Not Mediated by PON2. Neurotoxicology, 48,166-170. http://dx.doi.org/10.1016/j.neuro.2015.03.012

[35] Yan, J., Sun, J., Huang, L., Fu, Q. and Du, G. (2014) Simvastatin Prevents Neuroinflammation by Inhibiting N-Methyl-D-Aspartic Acid Receptor 1 in 6-Hydroxydopamine-Treated PC-12 Cells. Journal of Neuroscience Research, 5, 634-640. http://dx.doi.org/10.1002/jnr.23329

[36] Kumar, A., Sharma, N., Gupta, A., Kalonia, H. and Mishra, J. (2012) Neuroprotective Potential of Atorvastatin, Simvastatin (HMG-CoA Reductase Inhibitors) against 6-Hydroxydopamine (6-OHDA) Induced Parkinson-Like Symptoms. Brain Research, 1471, 13-22.

[37] Perez, H.J., Carrillo, S.C., Garcia, E., et al. (2014) Neuroprotective Effect of Silymarin in a MPTP Mouse Model of Parkinson's Disease. Toxicology, 319, 38-43.

[38] Geed, M. and Garabadu, D. (2014) Silibinin Pretreatment Attenuates Biochemical and Behavioral Changes Induced by Intrastriatal MPP+ Injection in Rats. Pharmacology Biochemistry and Behavior, 117, 92-103. http://dx.doi.org/10.1016/j.pbb.2013.12.008

[39] Kim, M., Cho, K.H., Shin, M.S., et al. (2014) Berberine Prevents Nigrostriatal Dopaminergic Neuronal Loss and Suppresses Hippocampal Apoptosis in Mice with Parkinson's Disease. International Journal of Molecular Medicine, 4, 870-878. http://dx.doi.org/10.3892/ijmm.2014.1656

[40] Yadav, S.K., Prakash, J., Chouhan, S., et al. (2014) Comparison of the Neuroprotective Potential of Mucuna pruriens Seed Extract with Estrogen in 1-Methyl-4-Phenyl-1,2,3,6-Tetrahydropyridine (MPTP)-Induced PD Mice Model. Neurochemistry International, 65, 1-13.

[41] Fu, R.H., Wang, Y.C., Chen, C.S., et al. (2014) Acetylcorynoline Attenuates Dopaminergic Neuron Degeneration and $\alpha$-Synuclein Aggregation in Animal Models of Parkinson's Disease. Neuropharmacology, 82, 108-120. http://dx.doi.org/10.1016/j.neuropharm.2013.08.007

[42] Lin, Y., Shi, R., Wang, X. and Shen, H.M. (2008) Luteolin, a Flavonoid with Potential for Cancer Prevention and Therapy. Current Cancer Drug Targets, 7, 634-646. http://dx.doi.org/10.2174/156800908786241050

[43] Fu, R.H., Harn, H.J., Liu, S.P., et al. (2014) N-Butylidenephalide Protects against Dopaminergic Neuron Degeneration and $\alpha$-Synuclein Accumulation in Caenorhabditis elegans Models of Parkinson's Disease. PLoS ONE, 9, e85305. http://dx.doi.org/10.1371/journal.pone.0085305

[44] Jayaraj, R.L., Elangovan, N., Manigandan, K., Singh, S. and Shukla, S. (2014) CNB-001 a Novel Curcumin Derivative, Guards Dopamine Neurons in MPTP Model of Parkinson's Disease. BioMed Research International, 2014, Article ID: 236182. http://dx.doi.org/10.1155/2014/236182

[45] Valera, E., Mante, M., Anderson, S., Rockenstein, E. and Masliah, E. (2015) Lenalidomide Reduces Microglial Activation and Behavioral Deficits in a Transgenic Model of Parkinson's Disease. Journal of Neuroinflammation, $12,93$.

[46] Li, D.W., Li, G.R., Lu, Y., et al. (2013) $\alpha$-Lipoic Acid Protects Dopaminergic Neurons against MPP+-Induced Apoptosis by Attenuating Reactive Oxygen Species Formation. International Journal of Molecular Medicine, 32, 108-114.

[47] Hegarty, S.V., O’Keeffe, G.W. and Sullivan, A.M. (2014) Neurotrophic Factors: From Neurodevelopmental Regulators to Novel Therapies for Parkinson's Disease. Neural Regeneration Research, 9, 1708-1711.

[48] Yasuda, T. and Mochizuki, H. (2010) Use of Growth Factors for the Treatment of Parkinson's Disease. Expert Review 
of Neurotherapeutics, 6, 915-924. http://dx.doi.org/10.1586/ern.10.55

[49] Weissmiller, A.M. and Wu, C. (2012) Current Advances in Using Neurotrophic Factors to Treat Neurodegenerative Disorders. Translational Neurodegeneration, 1, 14.

[50] Neto, F.L., Borges, G., Torres-Sanchez, S., Mico, J.A. and Berrocoso, E. (2011) Neurotrophins Role in Depression Neurobiology: A Review of Basic and Clinical Evidence. Current Neuropharmacology, 4, 530-552. http://dx.doi.org/10.2174/157015911798376262

[51] Xu, H., Belkacemi, L., Jog, M., Parrent, A. and Hebb, M.O. (2013) Neurotrophic Factor Expression in Expandable Cell Populations from Brain Samples in Living Patients with Parkinson's Disease. The Journal of the Federation of American Societies for Experimental Biology, 10, 4157-4168. http://dx.doi.org/10.1096/fj.12-226555

[52] Falk, T., Gonzalez, R.T. and Sherman, S.J. (2010) The Yin and Yang of VEGF and PEDF: Multifaceted Neurotrophic Factors and Their Potential in the Treatment of Parkinson's Disease. International Journal of Molecular Sciences, 11, 2875-2900.

[53] Ramaswamy, S., Soderstrom, K.E. and Kordower, J.H. (2009) Trophic Factors Therapy in Parkinson's Disease. Progress in Brain Research, 175, 201-216. http://dx.doi.org/10.1016/S0079-6123(09)17514-3

[54] Rangasamy, S.B., Soderstrom, K., Bakay, R.A. and Kordower, J.H. (2010) Neurotrophic Factor Therapy for Parkinson's Disease. Progress in Brain Research, 184, 237-264. http://dx.doi.org/10.1016/S0079-6123(10)84013-0

[55] Aloe, L., Rocco, M.L., Bianchi, P. and Manni, L. (2012) Nerve Growth Factor: From the Early Discoveries to the Potential Clinical Use. Journal of Translational Medicine, 10, 239.

[56] Rangasamy, S.B., Soderstrom, K., Bakay, R.A. and Kordower, J.H. (2010) Neurotrophic Factor Therapy for Parkinson's Disease. Progress in Brain Research, 184, 237-264.

[57] Berghauzen-Maciejewska, K., Wardas, J., Kosmowska, B., et al. (2015) Alterations of BDNF and trkB mRNA Expression in the 6-Hydroxydopamine-Induced Model of Preclinical Stages of Parkinson's Disease: An Influence of Chronic Pramipexole in Rats. PLOS ONE, 10, e0117698.

[58] Vairo, F., Sperb-Ludwig, F., Wilke, M., et al. (2015) Brain-Derived Neurotrophic Factor Expression Increases after Enzyme Replacement Therapy in Gaucher Disease. Journal of Neuroimmunology, 278, 190-193. http://dx.doi.org/10.1016/j.jneuroim.2014.11.005

[59] Ventriglia, M., Zanardini, R., Bonomini, C., et al. (2013) Serum Brain-Derived Neurotrophic Factor Levels in Different Neurological Diseases. BioMed Research International, 2013, 901082.

[60] Frazzitta, G., Maestri, R., Ghilardi, M., et al. (2014) Intensive Rehabilitation Increases BDNF Serum Levels in Parkinsonian Patients: A Randomized Study. Neurorehabilitation and Neural Repair, 2, 163-168. http://dx.doi.org/10.1177/1545968313508474

[61] Frazzitta, G., Maestri, R., Bertotti, G., et al. (2015) Intensive Rehabilitation Treatment in Early Parkinson's Disease: A Randomized Pilot Study with a 2-Year Follow-Up. Neurorehabilitation and Neural Repair, 2,123-131. http://dx.doi.org/10.1177/1545968314542981

[62] Angelucci, F., Peppe, A., Carlesimo, G.A., et al. (2015) A Pilot Study on the Effect of Cognitive Training on BDNF Serum Levels in Individuals with Parkinson's Disease. Frontiers in Human Neuroscience, 9, 130.

[63] D’Anglemont de Tassigny, X., Pascual, A. and López-Barneo, J. (2015) GDNF-Based Therapies, GDNF-Producing Interneurons, and Trophic Support of the Dopaminergic Nigrostriatal Pathway. Implications for Parkinson's Disease. Frontiers in Neuroanatomy, 9, 10.

[64] Li, F., Wang, M., Zhu, S., Li, L., Xiong, Y. and Gao, D.S. (2013) The Potential Neuroprotection Mechanism of GDNF in the 6-OHDA-Induced Cellular Models of Parkinson's Disease. Journal of Neuropathology \& Experimental Neurology, 70, 736-747. http://dx.doi.org/10.1007/s10571-013-9957-0

[65] Lei, Z., Jiang, Y., Li, T., Zhu, J. and Zeng, S. (2011) Signaling of Glial Cell Line-Derived Neurotrophic Factor and Its Receptor GFR $\alpha 1$ Induce Nurr1 and Pitx3 to Promote Survival of Grafted Midbrain-Derived Neural Stem Cells in a Rat Model of Parkinson disease. Journal of Neuropathology \& Experimental Neurology, 70, 736-747. http://dx.doi.org/10.1097/NEN.0b013e31822830e5

[66] Mickiewicz, A.L. and Kordower, J.H. (2011) GDNF Family Ligands: A Potential Future for Parkinson's Disease Therapy. CNS \& Neurological Disorders Drug Targets, 10, 703-711. http://dx.doi.org/10.2174/187152711797247876

[67] Peng, Y.S., Lai, P.L., Peng, S., et al. (2014) Glial Cell Line-Derived Neurotrophic Factor Gene Delivery via a Polyethylene Imine Grafted Chitosan Carrier. Journal of International Journal of Nanomedicine, 9, 3163-3174.

[68] Migliore, M.M., Ortiz, R., Dye, S., Campbell, R.B., Amiji, M.M. and Waszczak, B.L. (2014) Neurotrophic and Neuroprotective Efficacy of Intranasal GDNF in a Rat Model of Parkinson's Disease. Neuroscience, 274, 11-23. http://dx.doi.org/10.1016/j.neuroscience.2014.05.019

[69] Pronto-Laborinho, A.C., Pinto, S. and de Carvalho, M. (2014) Roles of Vascular Endothelial Growth Factor in Amyo- 
trophic Lateral Sclerosis. BioMed Research International, 2014, Article ID: 947513. http://dx.doi.org/10.1155/2014/947513

[70] Falk, T., Gonzalez, R.T. and Sherman, S.J. (2010) The Yin and Yang of VEGF and PEDF: Multifaceted Neurotrophic Factors and Their Potential in the Treatment of Parkinson's Disease. International Journal of Molecular Sciences, 11, 2875-900. http://dx.doi.org/10.3390/ijms11082875

[71] Zhang, L.Y., Fan, Y.Y. and Liu, Z. (2009) VEGF and Central Nervous System Diseases. Journal of Zhejiang University Medical Sciences, 38, 644-648.

[72] Mihci, E., Ozkaynak, S.S., Sallakci, N., Kizilay, F. and Yavuzer, U. (2011) VEGF Polymorphisms and Serum VEGF Levels in Parkinson's Disease. Neuroscience Letters, 494, 1-5. http://dx.doi.org/10.1016/j.neulet.2011.02.027

[73] Yue, X., Hariri, D.J., Caballero, B., et al. (2014) Comparative Study of the Neurotrophic Effects Elicited by VEGF-B and GDNF in Preclinical in Vivo Models of Parkinson's Disease. Neuroscience, 258, 385-400. http://dx.doi.org/10.1016/j.neuroscience.2013.11.038

[74] Itoh, N. and Ohta, H. (2013) Roles of FGF20 in Dopaminergic Neurons and Parkinson's Disease. Frontiers in Molecular Neuroscience, 6, 15.

[75] Krejci, P., Prochazkova, J., Bryja, V., Kozubik, A. and Wilcox, W.R. (2009) Molecular Pathology of the Fibroblast Growth Factor Family. Human Mutation, 30, 1245-1255. http://dx.doi.org/10.1002/humu.21067

[76] Zhu, R., Zhu, Y., Liu, X., He, Z. (2014) Fibroblast Growth Factor 20 (FGF20) Gene Polymorphism and Risk of Parkinson's Disease: A Meta-Analysis. Neurological Sciences, 35, 1889-1894. http://dx.doi.org/10.1007/s10072-014-1853-y

[77] Sleeman, I.J., Boshoff, E.L. and Duty, S. (2012) Fibroblast Growth Factor-20 Protects against Dopamine Neuron Loss in Vitro and Provides Functional Protection in the 6-Hydroxydopamine-Lesioned Rat Model of Parkinson's Disease. Neuropharmacology, 63, 1268-1277. http://dx.doi.org/10.1016/j.neuropharm.2012.07.029

[78] Kemppainen, S., Lindholm, P., Galli, E., et al. (2015) Cerebral Dopamine Neurotrophic Factor Improves Long-Term Memory in APP/PS1 Transgenic Mice Modeling Alzheimer's Disease as Well as in Wild-Type Mice. Behavioural Brain Research, 291, 1-11. http://dx.doi.org/10.1016/j.bbr.2015.05.002

[79] Lindholm, P. and Saarma, M. (2010) Novel CDNF/MANF Family of Neurotrophic Factors. Developmental Neurobiology, 70, 360-371. http://dx.doi.org/10.1002/dneu.20760

[80] Mei, J.M. and Niu, C.S. (2014) Effects of CDNF on 6-OHDA-Induced Apoptosis in PC12 Cells via Modulation of Bcl-2/Bax and Caspase-3 Activation. Neurological Sciences, 35, 1275-1280. http://dx.doi.org/10.1007/s10072-014-1700-1

[81] Airavaara, M., Harvey, B.K., Voutilainen, M.H., et al. (2012) CDNF Protects the Nigrostriatal Dopamine System and Promotes Recovery after MPTP Treatment in Mice. Cell Transplantation, 21, 1213-1223. http://dx.doi.org/10.3727/096368911X600948

[82] Nadella, R., Voutilainen, M.H., Saarma, M., et al. (2014) Transient Transfection of Human CDNF Gene Reduces the 6-Hydroxydopamine-Induced Neuroinflammation in the Rat Substantia Nigra. Journal of Neuroinflammation, 11, 209. http://dx.doi.org/10.1186/s12974-014-0209-0

[83] Gasmi, M., Herzog, CD., Brandon, EP., et al. (2007) Striatal Delivery of Neurturin by CERE-120, an AAV2 Vector for the Treatment of Dopaminergic Neuron Degeneration in Parkinson's Disease. Molecular Therapy, 15, 62-68. http://dx.doi.org/10.1038/sj.mt.6300010

[84] Herzog, C.D., Brown, L., Kruegel, B.R., et al. (2013) Enhanced Neurotrophic Distribution, Cell Signalling and Neuroprotection Following Substantia Nigral versus Striatal Delivery of AAV2-NRTN(CERE-120). Neurobiology of Disease, 58, 38-48. http://dx.doi.org/10.1016/j.nbd.2013.04.011

[85] Marks Jr., W.J., Ostrem, J.L., Verhagen, L., et al. (2008) Safety and Tolerability of Intraputaminal Delivery of CERE-120 (Adeno-Associated Virus Serotype 2-Neurturin) to Patients with Idiopathic Parkinson's Disease: An Open-Label, Phase 1 Trial. The Lancet Neurology, 5, 400-408. http://dx.doi.org/10.1016/S1474-4422(08)70065-6

[86] Marks Jr., W.J., Bartus, R.T., Siffert, J., et al. (2010) Gene Delivery of AAV2-Neurturin for Parkinson’s Disease: A Double-Blind, Randomized, Controlled Trial. The Lancet Neurology, 12, 1164-1172. http://dx.doi.org/10.1016/S1474-4422(10)70254-4

[87] Liu, H., Zhou, Y., Chen, S., et al. (2013) Current Sustained Delivery Strategies for the Design of Local Neurotrophic Factors in Treatment of Neurological Disorders. Asian Journal of Pharmaceutical Sciences, 8, 269-277.

[88] Lyons, M.K. (2011) Deep Brain Stimulation: Current and Future Clinical Applications. Mayo Clinic Proceedings, 7, 662-672. http://dx.doi.org/10.4065/mcp.2011.0045

[89] Williams, N.R. and Okun, M.S. (2013) Deep Brain Stimulation (DBS) at the Interface of Neurology and Psychiatry. Journal of Clinical Investigation, 123, 4546-456. http://dx.doi.org/10.1172/JCI68341 
[90] Shimo, Y. (2012) The Role of Neurologists in DBS Treatment on Parkinson's Disease. Rinsho Shinkeigaku, 52, 1103-1105. http://dx.doi.org/10.5692/clinicalneurol.52.1103

[91] Shah, R.S., Chang, S.Y., Min, H.K., et al. (2010) Deep Brain Stimulation Technology at the Cutting Edge. Journal of Clinical Neurology, 4, 167-182. http://dx.doi.org/10.3988/jcn.2010.6.4.167

[92] Okun, M.S. (2012) The Transition of Deep Brain Stimulation from Disease Specific to Symptom Specific Indications. Rinsho Shinkeigaku, 52, 891-895. http://dx.doi.org/10.5692/clinicalneurol.52.891

[93] Oluigbo, C.O., Salma, A. and Rezai, A.R. (2012) Deep Brain Stimulation for Neurological Disorders. IEEE Reviews in Biomedical Engineering, 5, 88-99. http://dx.doi.org/10.1109/RBME.2012.2197745

[94] Chicken, S. and Nambu, A. (2015) Mechanism of Deep Brain Stimulation: Inhibition, Excitation, or Disruption? The Neuroscientist, pii: 1073858415581986. http://dx.doi.org/10.1177/1073858415581986

[95] Yamada, H. (2012) The Indication of DBS in Parkinson's Disease from a Neurological Standpoint. Rinsho Shinkeigaku, 52, 1098-1099. http://dx.doi.org/10.5692/clinicalneurol.52.1098

[96] de Hemptinne, C., Swann, N.C., Ostrem, J.L., et al. (2015) Therapeutic Deep Brain Stimulation Reduces Cortical Phase-Amplitude Coupling in Parkinson's Disease. Nature Neuroscience, 5, 779-786. http://dx.doi.org/10.1038/nn.3997

[97] Lin, Y., Li, W., Tan, C., et al. (2014) Meta-Analysis Comparing Deep Brain Stimulation of the Globus Pallidus and Subthalamic Nucleus to Treat Advanced Parkinson's Disease. Journal of Neurosurgery, 121,709-718. http://dx.doi.org/10.3171/2014.4.JNS131711

[98] Odekerken, V.J., van Laar, T., Staal, M.J., et al. (2013) Subthalamic Nucleus versus Globus Pallidus Bilateral Deep Brain Stimulation for Advanced Parkinson's Disease (NSTAPS study): A Randomized Controlled Trial. The Lancet Neurology, 12, 37-44. http://dx.doi.org/10.1016/S1474-4422(12)70264-8

[99] Pollak, P. (2013) Deep Brain Stimulation for Parkinson’s Disease-Patient Selection. Handbook of Clinical Neurology, 116, 97-105. http://dx.doi.org/10.1016/B978-0-444-53497-2.00009-7

[100] Oluigbo, C.O., Salma, A. and Rezai, A.R. (2012) Deep Brain Stimulation for Neurological Disorders. EEE Reviews in Biomedical Engineering, 5, 88-99. http://dx.doi.org/10.1109/RBME.2012.2197745

[101] Glannon, W. (2010) Consent to Deep Brain Stimulation for Neurological and Psychiatric Disorders. Journal of Clinical Ethics, 21, 104-111.

[102] Groiss, S.J., Wojtecki, L., Südmeyer, M. and Schnitzler, A. (2009) Deep Brain Stimulation in Parkinson’s Disease. Therapeutic Advances in Neurological Disorders, 6, 20-28. http://dx.doi.org/10.1177/1756285609339382

[103] Chen, X.L., Xiong, Y.Y., Xu, G.L. and Liu, X.F. (2013) Deep Brain Stimulation. Interventional Neurology, 1, $200-212$. http://dx.doi.org/10.1159/000353121

[104] Shipton, E.A. (2012) Movement Disorders and Neuromodulation. Neurology Research International, 2012, Article ID: 309431. http://dx.doi.org/10.1155/2012/309431

[105] Lunn, J.S., Sakowski, S.A., Hur, J. and Feldman, E.L. (2011) Stem Cell Technology for Neurodegenerative Diseases. Annals of Neurology, 70, 353-361. http://dx.doi.org/10.1002/ana.22487

[106] Larijani, B., Esfahani, E.N., Amini, P., et al. (2012) Stem Cell Therapy in Treatment of Different Diseases. Acta Medica Iranica, 50, 79-96.

[107] Dantuma, E., Merchant, S. and Sugaya, K. (2010) Stem Cells for the Treatment of Neurodegenerative Diseases. Stem Cell Research \& Therapy, 1, 37. http://dx.doi.org/10.1186/scrt37

[108] Kim, S.U., Lee, H.J. and Kim, Y.B. (2013) Neural Stem Cell-Based Treatment of Neurodegenerative Diseases. Neuropathology, 33, 491-504. http://dx.doi.org/10.1111/neup.12020

[109] Sanchez-Danes, A., Consigliore, A., Richard, Y., et al. (2012) Efficient Generation of A9 Midbrain Dopaminergic neurons by Lentiviral Delivery of LMX1A in Human Embryonic Stem Cells and Induced Pluripotent Stem Cells. $\mathrm{Hu}$ man Gene Therapy, 1, 56-69. http://dx.doi.org/10.1089/hum.2011.054

[110] Zhang, P., Xia, N. and Reijo Pera, R.A. (2014) Directed Dopaminergic Neuron Differentiation from Human Pluripotent Stem Cells. Journal of Visualized Experiments, 91, e51737. http://dx.doi.org/10.3791/51737

[111] Gonzalez, C., Bonilla, S., Flores, A.I., Cano, E. and Liste, I. (2015) An Update on Human Stem Cell-Based Therapy in Parkinson's Disease. Current Stem Cell Research \& Therapy.

[112] Lindvall, O. and Kokaia, Z. (2010) Stem Cells in Human Neurodegenerative Disorders-Time for Clinical Translation? Journal of Clinical Investigation, 120, 29-40. http://dx.doi.org/10.1172/JCI40543

[113] Capitelli, C.S., Lopes, C.S., Alves, A.C., et al. (2014) Opposite Effects of Bone Marrow-Derived Cells Transplantation in MPTP-Rat Model of Parkinson's Disease: A Comparison Study of Mononuclear and Mesenchymal Stem Cells. International Journal of Medical Sciences, 11, 1049-1064. http://dx.doi.org/10.7150/ijms.8182 
[114] Han, F., Wang, W., Chen, B., et al. (2015) Human Induced Pluripotent Stem Cell-Derived Neurons Improve Motor Asymmetry in a 6-Hydroxydopamine-Induced Rat Model of Parkinson’s Disease. Cytotherapy, 17, 665-679. http://dx.doi.org/10.1016/j.jcyt.2015.02.001

[115] Chen, L.W., Kuang, F., Wei, L.C., et al. (2011) Potential Application of Induced Pluripotent Stem Cells in Cell Replacement Therapy for Parkinson’s Disease. CNS \& Neurological Disorders Drug Targets, 4, 449-458. http://dx.doi.org/10.2174/187152711795563994

[116] Larijani, B., Esfahani, E.N., Amini, P., et al. (2012) Stem Cell Therapy in Treatment of Different Diseases. Acta Medica Iranica, 50, 79-96.

[117] Okano, H. and Yamanaka, S. (2014) iPS Cell Technologies: Significance and Applications to CNS Regeneration and Disease. Molecular Brain, 7, 22. http://dx.doi.org/10.1186/1756-6606-7-22

[118] Buzhor, E., Leshansky, L., Blumenthal, J., et al. (2014) Cell-Based Therapy Approaches: The Hope for Incurable Diseases. Regenerative Medicine, 9, 649-672. http://dx.doi.org/10.2217/rme.14.35

[119] Maguire, G. and Friedman, P. (2015) Systems Biology Approach to Developing S²R-Based "Systems Therapeutics” and Naturally Induced Pluripotent Stem Cells. World Journal of Stem Cells, 7, 745-756. http://dx.doi.org/10.4252/wjsc.v7.i4.745

[120] Ambasudhan, R., Dolatabadi, N., Nutter, A., et al. (2014) Potential for Cell Therapy in Parkinson’s Disease Using Genetically Programmed Human Embryonic Stem Cell-Derived Neural Progenitor Cells. Journal of Comparative Neurology, 522, 2845-2856. http://dx.doi.org/10.1002/cne.23617

[121] Steece-Collier, K., Rademacher, D.J., Soderstrom, K. (2012) Anatomy of Graft-Induced Dyskinesias: Circuit Remodeling in the Parkinsonian Striatum. Basal Ganglia, 2, 15-30. http://dx.doi.org/10.1016/j.baga.2012.01.002

[122] Yin, H., Kanasty, R.L., Eltoukhy, A.A., et al. (2014) Non-Viral Vectors for Gene-Based Therapy. Nature Reviews Genetics, 8, 541-555. http://dx.doi.org/10.1038/nrg3763

[123] Huang, P.I., Lo, W.L., Cherng, J.Y., et al. (2012) Non-Viral Delivery of RNA Interference Targeting Cancer Cells in Cancer Gene Therapy. Current Gene Therapy, 4, 275-284. http://dx.doi.org/10.2174/156652312802083576

[124] Asadi-Moghaddam, K. and Chiocca, E.A. (2009) Gene- and Viral-Based Therapies for Brain Tumors. Neurotherapeutics, 3, 547-557. http://dx.doi.org/10.1016/j.nurt.2009.04.007

[125] Coune, P.G., Schneider, B.L. and Aebischer, P. (2012) Parkinson’s Disease: Gene Therapies. Cold Spring Harbor Perspectives in Medicine, 4, a009431. http://dx.doi.org/10.1101/cshperspect.a009431

[126] Feng, L.R. and Maquire-Zeiss, K.A. (2010) Gene Therapy in Parkinson's Disease: Rationale and Current Status. CNS Drugs, 3, 177-192. http://dx.doi.org/10.2165/11533740-000000000-00000

[127] Bartus, R.T., Weinberg, M.S. and Samulski, R.J. (2014) Parkinson’s Disease Gene Therapy: Success by Design Meets Failure by Efficacy. Molecular Therapy, 3, 487-497. http://dx.doi.org/10.1038/mt.2013.281

[128] Nakata, Y., Yasuda, T. and Mochizuki, H. (2012) Recent Progress in Gene Therapy for Parkinson’s Disease. Current Molecular Medicine, 10, 1311-1318. http://dx.doi.org/10.2174/156652412803833580

[129] Ghosh, S., Thrasher, A.J., Gaspar, H.B. (2015) Gene Therapy for Monogenic Disorders of the Bone Marrow. British Journal of Haematology. http://dx.doi.org/10.1111/bjh.13520

[130] Wu, C. and Dunbar, C.E. (2011) Stem Cell Gene Therapy: The Risks of Insertional Mutagenesis and Approaches to Minimize Genotoxicity. Frontiers in Medicine, 4, 356-371. http://dx.doi.org/10.1007/s11684-011-0159-1

[131] Nagabhushan Kalburgi, S., Khan, N.N. and Gray, S.J. (2013) Recent Gene Therapy Advancements for Neurological Diseases. Discovery Medicine, 81, 111-119.

[132] Gray, S.J. (2013) Gene Therapy and Neurodevelopmental Disorders. Neuropharmacology, 68, 136-142. http://dx.doi.org/10.1016/j.neuropharm.2012.06.024

[133] Gan, Y., Jing, Z., Stetler, R.A. and Cao, G. (2013) Gene Delivery with Viral Vectors for Cerebrovascular Diseases. Frontiers in Bioscience, 5, 188-203.

[134] Christine, C.W., Starr, P.A., Larson, P.S., et al. (2012) Safety and Tolerability of Putamenal AADC Gene Therapy for Parkinson's Disease. Neurology, 73, 1662-1669. http://dx.doi.org/10.1212/WNL.0b013e3181c29356

[135] Eberling, J.L., Jagust, W.J., Christine, C.W., et al. (2008) Results from a Phase I Safety Trial of hAADC Gene Therapy for Parkinson's Disease. Neurology, 70, 1980-1983. http://dx.doi.org/10.1212/01.wnl.0000312381.29287.ff

[136] Mittermeyer, G., Christine, C.W., Rosenbluth, K.H., et al. (2012) Long-Term Evaluation of Phase 1 Study of AADC Gene Therapy for Parkinson's Disease. Human Gene Therapy, 4, 377-381. http://dx.doi.org/10.1089/hum.2011.220

[137] Muramatsu, S. (2010) The Current Status of Gene Therapy for Parkinson's Disease. Annual Review of Neuroscience, 2, 92-95. http://dx.doi.org/10.5214/ans.0972-7531.1017209

[138] Kapllitt, M.G., Feigin, A., Tang, C., et al. (2007) Safety and Tolerability of Gene Therapy with a Adeno-Associated 
Virus (AAV) Borne GAD Gene for Parkinson’s Disease: An Open-Label, Phase I Trial. The Lancet, 369, 2097-2105. http://dx.doi.org/10.1016/S0140-6736(07)60982-9

[139] LeWitt, P.A., Rezai, A.R., Leehey, M.A., et al. (2011) AAV2-GAD Gene Therapy for Advanced Parkinson’s Disease: A Double-Blind, Sham-Surgery Controlled, Randomized Trial. The Lancet Neurology, 4, 309-319. http://dx.doi.org/10.1016/S1474-4422(11)70039-4

[140] Tabrez, S., Jabir, N.R., Shakil, S., et al. (2012) A Synopsis on the Role of Tyrosine Hydroxylase in Parkinson's Disease. CNS \& Neurological Disorders Drug Targets, 4, 395-409. http://dx.doi.org/10.2174/187152712800792785

[141] Cederfjäll, E., Sahin, G., Kirik, D. and Björklund, T. (2012) Design of a Single AAV for Coexpression of TH and GCH1 to Establish Continuous DOPA Synthesis in a Rat Model of Parkinson's Disease. Molecular Therapy, 7, 1315-1326. http://dx.doi.org/10.1038/mt.2012.1

[142] Sun, M., Kong, L., Wang, X., et al. (2004) Coexpression of Tyrosine Hydroxylase, GTP Cyclohydrolase I, Aromatic Amino Acid Decarboxylase, and Vesicular Monoamine Transporter 2 from a Helper Virus-Free Herpes Simplex Virus Type 1 Vector Supports High-Level, Long-Term Biochemical and Behavioral Correction of a Rat Model of Parkinson's Disease. Human Gene Therapy, 12, 177-196. http://dx.doi.org/10.1089/hum.2004.15.1177

[143] Zheng, D., Jiang, X., Zhao, J., Duan, D., et al. (2013) Subthalamic hGAD65 Gene Therapy and Striatum TH Gene Transfer in a Parkinson’s Disease Rat Model. Neural Plasticity, 2013, Article ID: 263287. http://dx.doi.org/10.1155/2013/263287

[144] Tsetsou, S, Rossetti, A.O., Michel, P., et al. (2015) News in Neurology 2014. Revue Médicale Suisse, 11, 91-96.

[145] Stewart, H.J., Fong-Wong, L. and Strickland, I. (2011) Stable Producer Cell Line for the Manufacture of a Lentiviral Vector for Gene Therapy of Parkinson's Disease. Human Gene Therapy, 3, 357-369. http://dx.doi.org/10.1089/hum.2010.142

[146] Palfi, S., Gurruchaga, J.M., Ralph, G.S., et al. (2014) Long-Term Safety and Tolerability of ProSavin, a Lentiviral Vector-Based Gene Therapy for Parkinson's Disease: A Dose Escalation, Open-Label, Phase 1/2 Trial. The Lancet, 383, 1138-1146. http://dx.doi.org/10.1016/S0140-6736(13)61939-X 